報文

\title{
主成分分析法を利用したガスクロマトグラムからの 重油と灯油の混合比の決定
}

\author{
三井 利幸 $^{\circledR *}$, 藤村 義和 ${ }^{* *}$ \\ (1994 年 12 月 13 日受付) \\ (1995 年 2 月 22 日審査終了)
}

\begin{abstract}
灯油と重油は同一成分を含有しており，現在行われている化学的分析法では灯油と重油の混合したも のから正確な混合比を求めることは困難である, そこで今回は, 重油と灯油の混合比既知試料と未知試 料について, ガスクロマトグラム中の各成分の変化割合を求めた後, 主成分分析法により主成分得点と 固有値から, 重油と灯油の混合比を求めた，その結果，誤差 $1.5 \%$ 以内で精度よく混合比が求められる ことが明らかとなった。
\end{abstract}

\section{1 緒言}

多変量解析法(1) -3) の分析化学への応用は, これまで に幾つか報告(45)されてきており, 著者らによってもガ スクロマトグラフィー6), 吸光光度法 ${ }^{7)}, \mathrm{X}$ 線回折法 ${ }^{899}$ の測定結果を用いた定量分析に多変量解析法が応用され 良好な結果が得られている。この方法を石油製品にも応 用し，ガソリンと灯油の混合比を求める方法について既

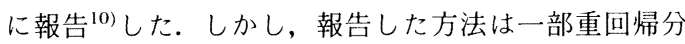
析法を用いているなど，改良すべき部分が認められたの で，今回はそれらを改良して重油と灯油の混合比の決定 に応用し, 主成分分析法による定量分析法をより完全な ものとしたので報告する.

裁判化学で取り扱われている石油製品として, しばし ば脱税を目的とした重油と灯油の混合物があり，その場 合当然重油と灯油の混合比が問題となる。一般に，重油 と灯油の混合比を求める目的で，試料をガスクロマトグ ラフィー (GC) で測定することが多いが, 重油と灯油 は構成成分のかなりの部分が重複しており，GC で得ら れたクロマトグラム上のピーク強度の単純な比較からで は, 正確な混合比を求めることは難しい。しかし, 重油 亡灯油中の複数の成分の変化割合を総合的に判断すれ ば,クロマトグラム上に観測される各成分の変化の状態

* 愛知県警察本部科学捜査研究所: 460 愛知県名古屋 市中区三の丸 2-1-1

** 中部大学工学部工業化学科: 487 愛知県春日井市松 本町 1200
から混合比を推定することは可能と考えられる.だが， 従来から行われている方法では, 複数のピークの変化割 合を同一次元で取り扱う有効な方法がなかったために， 複数のピークの変化割合から重油と灯油の混合比を求め ることは困難であった。

今回は多変量解析法の一種である主成分分析法を用い てこの問題を解決し，重油と灯油の混合比を求めること を試みた。

\section{2 試薬及び装置}

重油（A 重油）及び灯油は市販品をそのまま使用し た.

ガスクロマトグラフ（GC）はヒューレットパッカー ド製5890II 型を使用した。

測定は混合比既知試料として, 軽油の代替として用い られることのない灯油のみを除いた重油と灯油の混合比 $100: 0,80: 20,60: 40,40: 60,20: 80$ のもの 5 種類と 未知試料 8 種類について Table 1 の条件で測定した.

Fig. 1 に重油: 灯油の混合比 11:9 の試料を測定した 結果を示す.

\section{3 ピーク面積の数值化及び主成分分析法}

主成分分析を行うために，GC で得られるピークの面 積を用いてクロマトグラムの数值化を行った。まず重油 と灯油の混合比 $50: 50$ を測定し, 得られたクロマトグ ラム中のピーク面積 10000 以上の全 $(n$ 個 $)$ ピークの面 積を個々のピーク面積で除した。 その結果 $n \times n$ 個の数 
Table 1 Analytical conditions

\begin{tabular}{ll}
\hline Gas chromatograph & $:$ Hewlett Packard 5890 II \\
Colum & $:$ DB-1 $1.5 \mu \mathrm{m} ; 0.53 \mathrm{~mm}$ i.d. $\times 15 \mathrm{~m}$ \\
Column temp. & $: 70^{\circ} \mathrm{C}(1 \mathrm{~min})-16^{\circ} \mathrm{C} / \mathrm{min}-250^{\circ} \mathrm{C}(5$ \\
& $\min )$ \\
Injection temp. & $: 250^{\circ} \mathrm{C}$ \\
Carrier gas & $:$ He $10 \mathrm{ml} / \mathrm{min}$ \\
Detector & $:$ FID \\
Sample size & $: 1 \mu l$ \\
\hline
\end{tabular}

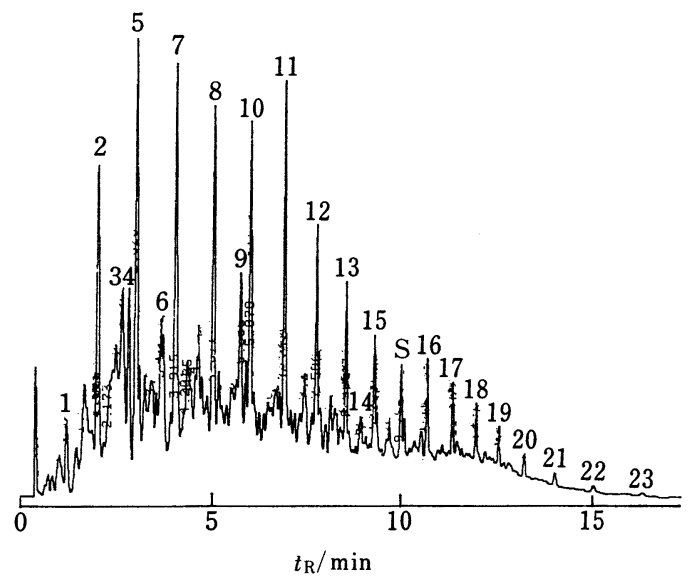

Fig. 1 Chromatogram of heavy oil and kerosene mixture (heavy oil : kerosene $=11: 9$ ) 1 23: selected peaks by quantification IV; $\mathrm{S}$ : selected specific peak by quantification IV

值が得られた.この $n \times n$ 個の数值を数量化理論第 IV 類で計算し, 主成分分析に使用可能な数值のみを抽出し た.

\section{3・1 数量化理論第 IV 類}

数量化理論第 IV 類は $m$ 個の試料から $n$ 個の測定値 が得られたとき, その $n$ 個の測定值間の類似性の程度 を見いだす方法である. 従って, 数量化理論第 IV 類で は試料中の各测定值 $n_{\mathrm{i}}(i=1,2,3, \cdots)$ 間において, 互 いに一定の規則に従って変化している割合が高いほど, 計算で得られた各試料中の同一保持時間を持つ測定值に 対する数値が絶対值 0.000 に近い值を示すことになる. そのため, 変化がランダムで一定の規則に従わない測定 值（主成分分析法には利用できない測定値）はこの方法 で除外される.今回は，この方法により，Fig. 1 に示し た 23 のピーク面積を特定のピーク面積で除し, 主成分
分析で重油と灯油の混合比を求めるために有効な Table 2 に示したような各試料に対する 23 個の数值（カテゴ リー）が抽出された。

なお, 各カテゴリーと試料中の重油の混合比との間の 相関係数（従来から行われている検量線）は 0.8656 か ら 0.9775 で, 最も高い相関関係を示した測定値（カテ ゴリー）はピーク番号 22 であった. しかしこのピーク は試料間での変化割合が小さく検量線として使用するに は不適当と考えられた。

\section{$3 \cdot 2$ 主成分分析法}

従来法では, 通常検量線は1試料中から得られる複 数の测定值の中から, 最も值線性を示すと思われる任意 の測定値を検查者が選択しているために，検査者によっ て測定值の選択が異なることがある. 更に 1 試料から 複数の測定值が得られているにもかかわらず, その中の 1 個しか利用していない. しかも既知試料間の測定値と それに対する濃度との変化状態に関して, 最小二乗法で 検量線 (二元一次方程式) を求めているにもかかわら す，同時に同一条件で測定した未知試料の濃度は, あら かじめ作成されている二元一次方程式に測定值を代入し て求められる. そのために, 未知試料の定量值の変動が 大きくなり, 定量值の信頼性が低下する原因の一つにな っている.

主成分分析法はこれらの問題を解決できる方法で, 次 に示すような特徴を持っている.

1) 1 試料中の複数の測定值（300〜 400 個まで用いて 計算可能) を，その内容の損失なしに 1 あるいは 2 個 程度の数值 (主成分得点) に凝縮できるため, 複数の测 定值を用いて定量することが可能となる，そのために， 測定值の中で数個の異常值があっても定量值にはほとん ど影響を与えない. 更に, 定量分析のための測定値選択 時に検査者の主観の入る可能性がほとんどない. 又, こ の方法は, 従来法である測定值と濃度との関係から1 本の検量線を作成し, その検量線に未知試料の測定值を 代入することにより定量する方法とは異なり，1個の試 料に対し複数の測定值を同時に用いるため, 結果として 測定誤差が相殺され精度の高い結果が得られる.

2) 末知試料の測定值を既知試料の測定值に加えて主 成分分析を行い，未知試料も含めた測定值間の相関関係 を求め, 従来法の $y$ 軸の数值に相当する主成分得点を 求めている.このために, 検量線に相当する測定值から 計算した数值と末知試料の測定值から計算した数値の双 方が，互いに関係を持って取り扱われている．つまり， 検量線の縦軸に相当する值は, 従来のピーク面積をその 
Table 2 Calculation of input data

\begin{tabular}{|c|c|c|c|c|c|c|c|c|c|c|c|c|c|}
\hline \multirow{2}{*}{$\begin{array}{l}\text { Peak }^{\text {a) }} \\
\text { number }\end{array}$} & \multirow{2}{*}{$\begin{array}{l}t_{\mathrm{R}} / \\
\min \end{array}$} & \multicolumn{5}{|c|}{ Input data ${ }^{b)}$} & \multirow[b]{2}{*}{$(-6)$} & \multirow[b]{2}{*}{$U_{1}$} & \multicolumn{4}{|c|}{ Deviation data ${ }^{c)}$} & \multirow[b]{2}{*}{$U_{6}$} \\
\hline & & $\begin{array}{c}1^{d)} \\
(100: 0)\end{array}$ & $\begin{array}{l}2^{\text {d) }} \\
0: 20\end{array}$ & $\begin{array}{l}3^{\text {d) }} \\
0: 40)\end{array}$ & $4^{\text {d) }}$ & $\begin{array}{l}5^{\text {d) }} \\
0: 80)\end{array}$ & & & $U_{2}$ & $U_{3}$ & $U_{4}$ & $U_{5}$ & \\
\hline 1 & 1.2 & 0.000 & 0.143 & 0.324 & 0.779 & 2.383 & 0.424 & 41.570 & 43.355 & 45.614 & 51.292 & 71.303 & 46.862 \\
\hline 2 & 2.0 & 0.263 & 0.582 & 1.484 & 3.835 & 11.705 & 2.063 & 42.204 & 43.017 & 45.316 & 51.308 & 71.366 & 46.791 \\
\hline 3 & 2.6 & 0.086 & 0.403 & 0.994 & 3.817 & 10.435 & 1.917 & 41.994 & 42.883 & 44.540 & 52.453 & 71.004 & 47.127 \\
\hline 4 & 2.8 & 0.303 & 0.448 & 0.963 & 2.339 & 6.406 & 1.299 & 42.098 & 42.790 & 45.246 & 51.809 & 71.208 & 46.849 \\
\hline 5 & 3.0 & 0.368 & 0.731 & 1.463 & 4.602 & 13.738 & 2.449 & 42.366 & 43.152 & 44.738 & 51.539 & 71.331 & 46.874 \\
\hline 6 & 3.7 & 0.250 & 0.227 & 0.838 & 1.975 & 5.264 & 1.072 & 42.222 & 42.090 & 45.590 & 52.105 & 71.063 & 46.931 \\
\hline 7 & 4.1 & 0.481 & 0.810 & 2.130 & 5.265 & 14.072 & 2.863 & 41.845 & 42.552 & 45.389 & 52.128 & 71.057 & 47.029 \\
\hline 8 & 5.1 & 0.641 & 0.885 & 1.792 & 4.261 & 10.396 & 2.363 & 41.788 & 42.517 & 45.226 & 52.599 & 70.921 & 46.949 \\
\hline 9 & 5.7 & 1.075 & 0.964 & 1.425 & 2.520 & 6.670 & 1.634 & 43.413 & 42.854 & 45.178 & 50.699 & 71.624 & 46.232 \\
\hline 10 & 6.0 & 0.578 & 0.780 & 1.482 & 3.458 & 7.723 & 1.971 & 41.479 & 42.303 & 45.169 & 53.236 & 70.674 & 47.166 \\
\hline 11 & 6.1 & 1.452 & 1.461 & 2.117 & 4.091 & 5.752 & 2.495 & 40.719 & 40.777 & 44.997 & 57.697 & 68.382 & 47.429 \\
\hline 12 & 7.7 & 1.030 & 0.991 & 1.332 & 2.144 & 3.513 & 1.480 & 41.838 & 41.391 & 45.293 & 54.241 & 70.250 & 46.987 \\
\hline 13 & 8.5 & 4.879 & 1.656 & 0.735 & 0.360 & 0.152 & 0.554 & 71.393 & 51.635 & 45.989 & 43.690 & 42.415 & 44.879 \\
\hline 14 & 8.7 & 2.121 & 1.319 & 0.596 & 0.187 & 0.044 & 0.348 & 68.505 & 57.527 & 47.630 & 42.031 & 40.073 & 44.235 \\
\hline 15 & 9.2 & 3.796 & 1.719 & 0.674 & 0.261 & 0.085 & 0.485 & 70.427 & 54.271 & 46.142 & 42.929 & 41.560 & 44.672 \\
\hline 16 & 10.6 & 2.714 & 1.542 & 0.706 & 0.199 & 0.059 & 0.425 & 69.130 & 56.486 & 47.466 & 41.997 & 40.486 & 44.435 \\
\hline 17 & 11.3 & 2.766 & 1.890 & 0.650 & 0.192 & 0.061 & 0.460 & 67.839 & 58.974 & 46.426 & 41.792 & 40.466 & 44.504 \\
\hline 18 & 11.9 & 1.812 & 1.160 & 0.463 & 0.117 & 0.044 & 0.323 & 68.309 & 58.008 & 46.995 & 41.529 & 40.375 & 44.783 \\
\hline 19 & 12.5 & 1.606 & 1.541 & 0.669 & 0.067 & 0.031 & 0.335 & 63.881 & 62.876 & 49.395 & 40.087 & 39.531 & 44.231 \\
\hline 20 & 13.1 & 1.233 & 0.902 & 0.396 & 0.064 & 0.023 & 0.252 & 66.974 & 52.529 & 48.148 & 40.681 & 39.759 & 44.909 \\
\hline 21 & 14.0 & 0.644 & 0.631 & 0.246 & 0.037 & 0.015 & 0.184 & 63.698 & 63.191 & 48.173 & 40.021 & 39.163 & 45.755 \\
\hline 22 & 15.0 & 0.549 & 0.439 & 0.239 & 0.028 & 0.010 & 0.176 & 65.538 & 60.004 & 49.941 & 39.325 & 38.420 & 46.772 \\
\hline 23 & 16.2 & 0.492 & 0.293 & 0.221 & 0.019 & 0.007 & 0.144 & 67.721 & 55.807 & 51.497 & 39.403 & 38.685 & 46.887 \\
\hline $\mathrm{S}$ & 9.9 & & & & & & & & & & & & \\
\hline
\end{tabular}

a) Category number. b) Number $1 \sim 5:$ known sample; Number 6: unknown sample (content of heavy oil: $55 \%$ ) (each peak area)/(Area of selected specific peak by quantification IV). c) Deviation $U: U_{\mathrm{i}, \mathrm{j}}=50.000+10 \times\left(x_{\mathrm{i}, \mathrm{j}}\right.$ $\left.-x_{\mathrm{j}}\right) / \sigma_{\mathrm{j}}$, here $U_{\mathrm{i}, \mathrm{j}}$, deviation of $j$ category in sample number $i ; x_{\mathrm{i}, \mathrm{j}}$, data of $j$ category in sample number $i ; x_{\mathrm{j}}$, mean of $j$ category; $\sigma_{\mathrm{j}}$, standard deviation of $j$ category. d) Heavy oil : kerosene $(\mathrm{v} / \mathrm{v}, \%)$. S: selected specific peak by quantification IV

ままを用いるのではなく，末知試料も含め計算された主 成分得点という形で表現される。今回は，1 試料当たり の 23 個の測定值を用い, 検量線に相当する 5 個の既知 試料と 1 個の未知試料の相関関係を求めて主成分得点 を決定しているために, 個々の未知試料に対し, 既知試 料の主成分得点は微妙に変動し, 常に同一数值にはなら ず, 6 試料間が互いに最も良い相関関係を示す数值とし て表される.このため, 未知試料の測定値に多少のばら つきがあっても定量値のばらつきは小さくなる. 従来法 での測定值に相当する主成分得点は, 濃度とは無関係に 測定值から求められた数值（今回は, 1 試料に対し 23 カテゴリ一, 検量線に相当する 5 試料と一つの未知試 料の合計 6 試料の $6 \times 23$ 行列から計算によって求めら れる.)である. 主成分分析での定量方法はこの主成分 得点を $y$ 軸に, 既知試料の濃度を $x$ 軸にして検量線を
作成し，未知試料の濃度を求めている.

一般的に言えば，主成分分析法は $m$ 個の試料中の $n$ 個のカテゴリーの持つ情報を, でき得る限り $m \times n$ 行列 中の内容を失うことなしに $p$ 個（通常 $p=1 \sim 3$ 程度） の列（主成分）に圧縮する方法である.だから，もし $n$ 個のカテゴリ一間に何の相関関係もないならば, $n$ 個の カテゴリー相互間のばらつきを評価することになる。こ のようなときには $n=p$ となり, 数量化理論第 IV 類で は各試料中のすべてのカテゴリーに対して, 計算で得ら れた数値が限りなく絶対值 0.0000 に近くなり定量は不 可能となる. 通常は $m$ 個の試料中の $n$ 個のカテゴリー は, 試料間で程度の差があるもののなんらかの相関関係 がある. 従って, $n$ 個のカテゴリーについて共通の相関 関係にある部分を抽出し, まず $n$ 個のカテゴリ一間で 最も共通部分の多い相関関係を抽出したものが第一主成 


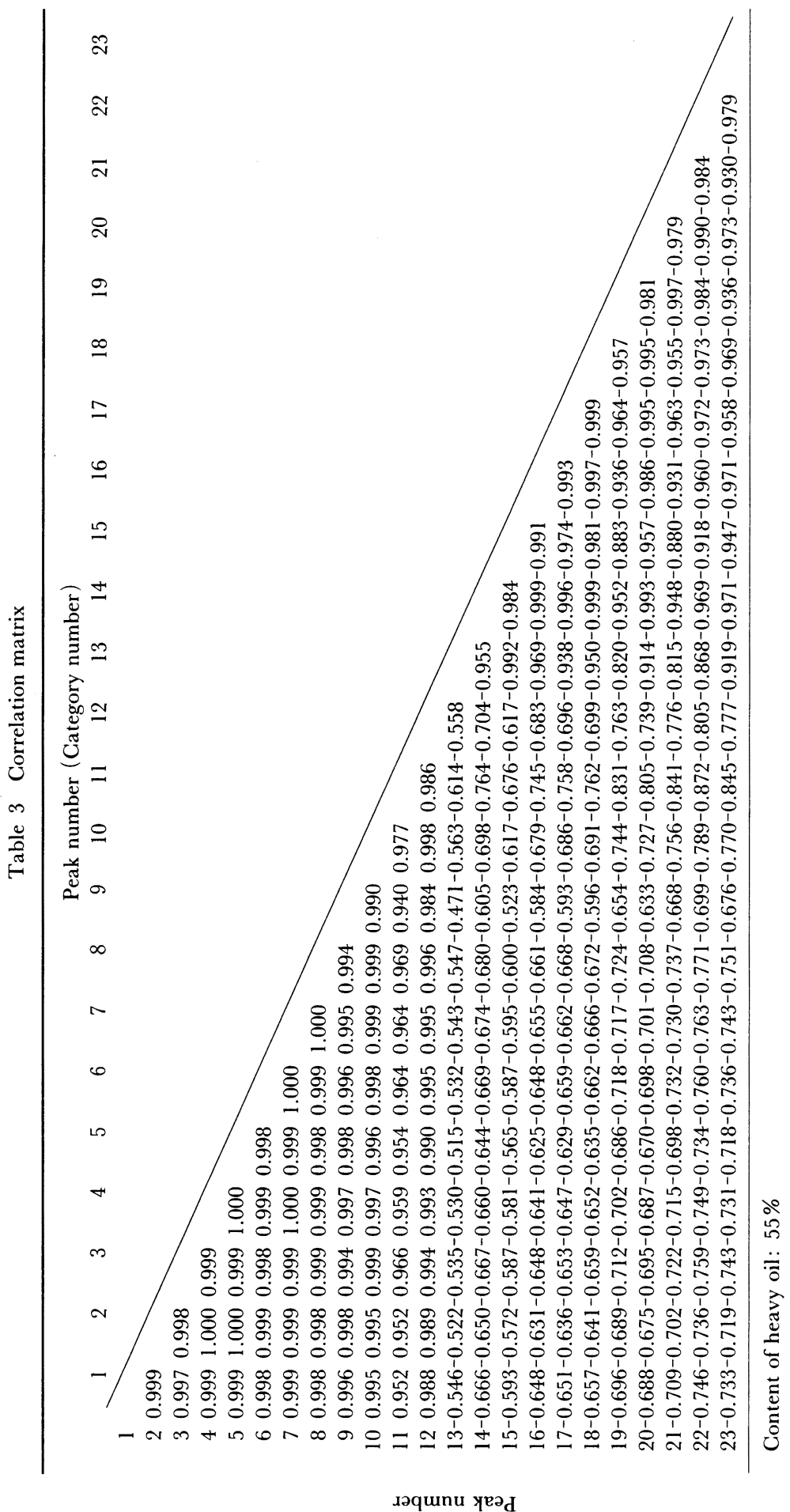


分 $(p=1)$ となる.この第一主成分が $m \times n$ 行列の内容 をよ゙の程度抽出しているかを，第一主成分に対する寄与 率 $\{($ 第一主成分に対する固有値/全固有値 $) \times 100\}$ で示 す. 次いで，第一主成分で抽出した残りから共通部分の 多い相関関係を持つ部分を抽出したものが，第二主成分 $(p=2)$ となり，第二主成分が $m \times n$ 行列の内容をどの 程度抽出してるかを第二主成分に対する寄与率 $\{($ 第二 主成分に対する固有値/全固有値 $) \times 100\}$ で示す.この ようにして, $m \times n$ 行列中の内容を種々の観点から捕ら え, 共通部分を順次抽出し, 第 $n$ 主成分まで求める. 得られた第 $n$ 主成分のうち, 該当する主成分に対する 固有值が 1.000 以上の各主成分 $(p$, 通常 1 2 個) を 用いて定量を行う.

この方法で Table 2 に示した 1 試料に対して 23 個の カテゴリーを偏差值に直したものを用いて, 23 カテゴ リ一間の相関関係を計算したところ, Table 3 に示した ような結果が得られた。この結果から明らかなように， カテゴリー番号 1 から 12 と 13 から 23 の二つのグ ループ間では相互に高い相関関係を示しているが，この 2 グループ間の相関関係は高くない。これは, 主として カテゴリー番号 1 から 12 は灯油に, 13 から 23 は重油 に由来するピークであることによるものと考えられる. カテゴリー番号 11 から 16 はそれぞれのグループ内で 他のカテゴリーと比較して相関係数值がやや低いが, こ れは灯油と重油双方に含有される成分ピークで, 混合比 の変化によるピーク面積の変化がほとんど灯油あるいは 重油のみに依存するピークと比較して, 幾分ランダムに 変化するためであることを示している．ただ，カテゴ リー番号 13 から 15 はこのカテゴリ一間内で相互に極 めて類似した変化をしていることが分かる.これらの相 関係数を基に主成分分析を行った結果を Table 4 に示 す.この結果から明らかなように， $6 \times 23$ 行列全体の内 容の $82.9 \%$ （固有值 19.074）を第一主成分で， $15.4 \%$ （3.537）を第二主成分で抽出していることになる.

\section{4 主成分得点による混合比の決定}

主成分分析で求めた各主成分亡 Table 2 の $6 \times 23$ 行 列からChart 1 に示した方法で主成分得点を計算した.

ここで, まず Chart 1 に示した第一, 第二主成分得点 を Chart 2 に示したようにして補正し総主成分得点を求 めた.

$$
W_{\mathrm{n}}=\left(W_{\mathrm{n} 1}-50\right) \times P_{1} / P_{\text {total }}+\left(W_{\mathrm{n} 2}-50\right) \times P_{2} / P_{\text {total }}+100
$$

ここで, $W_{\mathrm{n}}: n$ 番目の試料番号の総主成分得点, $W_{\mathrm{n} 1}: n$ 番目の試料番号の第一主成分得点, $W_{\mathrm{n} 2}: n$ 番目の試料
Table 4 Result of principal component analysis

\begin{tabular}{crrrrr}
\hline $\begin{array}{c}\text { Category } \\
\text { number }\end{array}$ & \multicolumn{5}{c}{ Factor loading } \\
\hline 1 & 1 & 2 & 3 & \multicolumn{1}{c}{4} & \multicolumn{1}{c}{5} \\
\hline 2 & 0.925 & 0.378 & 0.074 & -0.014 & 0.000 \\
3 & 0.916 & 0.395 & 0.052 & -0.015 & 0.000 \\
4 & 0.928 & 0.373 & 0.023 & 0.009 & 0.000 \\
5 & 0.914 & 0.363 & 0.037 & -0.021 & 0.000 \\
6 & 0.928 & 0.369 & 0.046 & -0.015 & 0.000 \\
7 & 0.930 & 0.366 & 0.023 & -0.021 & 0.000 \\
8 & 0.933 & 0.358 & 0.023 & -0.021 & 0.000 \\
9 & 0.892 & 0.448 & 0.032 & -0.044 & 0.000 \\
10 & 0.943 & 0.333 & 0.004 & 0.015 & 0.000 \\
11 & 0.962 & 0.202 & -0.122 & 0.121 & 0.000 \\
12 & 0.946 & 0.316 & -0.050 & 0.028 & 0.000 \\
13 & -0.788 & 0.542 & -0.295 & 0.012 & 0.000 \\
14 & -0.896 & 0.441 & -0.037 & 0.024 & 0.000 \\
15 & -0.836 & 0.516 & -0.186 & 0.013 & 0.000 \\
16 & -0.883 & 0.463 & -0.079 & -0.001 & 0.000 \\
17 & -0.888 & 0.452 & 0.023 & 0.070 & 0.000 \\
18 & -0.891 & 0.450 & -0.012 & 0.016 & 0.000 \\
19 & -0.908 & 0.331 & 0.247 & 0.057 & -0.040 \\
20 & -0.913 & 0.401 & 0.073 & 0.012 & 0.000 \\
21 & -0.914 & 0.312 & 0.250 & 0.057 & 0.040 \\
22 & -0.943 & 0.301 & 0.137 & -0.061 & 0.000 \\
23 & -0.928 & 0.326 & -0.036 & -0.178 & -0.000 \\
D.P.C. & 19.074 & 3.537 & 0.311 & 0.068 & 0.003 \\
\hline
\end{tabular}

Unknown sample: the content of heavy oil is $55 \%$.

D.P.C.: dispersion of principal component

番号の第二主成分得点, $P_{1}$ : 第一主成分に対する固有 值, $P_{2}$ : 第二主成分に対する固有值, $P_{\text {total }}$ : 第一, 第二 主成分に対する固有値の和である。こうして得られた総 主成分得点を用いて次式から混合比を求めた。

$$
\begin{aligned}
& \log W_{\mathrm{m}-1}=a \cdot C_{\mathrm{m}-1}+b \\
& \log W_{\mathrm{m}+1}=a \cdot C_{\mathrm{m}+1}+b \\
& \log W_{\mathrm{s}}=a \cdot x+b
\end{aligned}
$$

ここで, $W_{\mathrm{m}-1}$ : 未知試料より小さくてかつ未知試料に 最も近い既知試料の総主成分得点, $W_{\mathrm{m}+1}$ : 未知試料よ り大きくてかつ未知試料に最も近い既知試料の総主成分 得点, $C_{\mathrm{m}-1}: W_{\mathrm{m}-1}$ に対応する灯油と重油の混合比, $C_{\mathrm{m}+1}: W_{\mathrm{m}+1}$ に対応する灯油と重油の混合比, $W_{\mathrm{s}}$ : 未 知試料の総主成分得点, $x$ : 未知試料の灯油之重油の混 合比である. Chart 2 に示したように, 式(1)，（2)か ら $a, b$ を求め, 式( 3$)$ に代入して未知試料の重油と灯 油の混合比を求める. このようにして混合比の分かって いる試料を末知試料として測定し, 計算で求めた結果を 
First principal component score

Chart 1 Calculation of principal component score

$$
\sum_{j=1}^{23}\left\{\left(U_{1, \mathrm{j}}-50,000\right) \times F_{1, j}\right\} / D_{1}
$$

Example

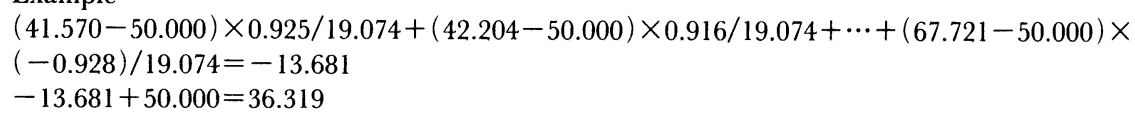

Second principal component score

$$
\begin{aligned}
& \sum_{j=1}^{23}\left\{\left(U_{1, \mathrm{j}}-50.000\right) \times F_{2, \mathrm{j}}\right\} / D_{2} \\
& \text { Example } \\
& (41.570-50.000) \times 0.378 / 3.537+(42.204-50.000) \times 0.395 / 3.537+\cdots+(67.721-50.000) \times \\
& 0.326 / 3.537=13.344 \\
& 13.344+50.000=63.344
\end{aligned}
$$

\begin{tabular}{cccc}
$\begin{array}{c}\text { Sample } \\
\text { number }\end{array}$ & $\begin{array}{c}\text { First principal } \\
\text { component score }\end{array}$ & $\begin{array}{c}\text { Second principal } \\
\text { component score }\end{array}$ & Heavy oil : kerosene \\
\hline 1 & 36.319 & 63.344 & $100: 0$ \\
2 & 41.420 & 50.582 & $80: 20$ \\
3 & 48.197 & 41.187 & $60: 40$ \\
4 & 56.063 & 41.913 & $40: 60$ \\
5 & 67.283 & 63.194 & $20: 80$ \\
6 & 50.719 & 39.780 & -
\end{tabular}

Sample number 1 5: known sample; Sample number 6: unknown sample (content of heavy oil: $55 \%$ ). $U_{1, \mathrm{j}}$ : deviation of sample number $1 ; F_{1, \mathrm{j}}$ : first factor loading; $D_{1}$ : first dispersion of principal component; $F_{2, \mathrm{j}}$ : second factor loading; $D_{2}$ : second dispersion of principal component

Chart 2 Calculation of heavy oil content from principal component score

Corrected first principal component score

$\{($ first principal component score $)-50.000)\} \times\{($ first dispersion of principal component $) /($ total dispersion of principal component $)\}+50.000$

Example

$(36.319-50.000) \times 19.074 / 22.611+50.000=38.459$

Corrected second principal component score

$\{($ second principal component score $)-50.000)\} \times\{($ second dispersion of principal component $) /($ total dispersion of principal component $)\}+50.000$

Example

$(63.344-50.000) \times 3.537 / 22.611+50.000=52.087$

Corrected total principal component score

$38.459+52.087=90.546$

\begin{tabular}{ccccc}
$\begin{array}{c}\text { Sample } \\
\text { number }\end{array}$ & $\begin{array}{c}\text { Corrected first principal } \\
\text { component score }\end{array}$ & $\begin{array}{c}\text { Corrected second principal } \\
\text { component score }\end{array}$ & $\begin{array}{c}\text { Corrected total } \\
\text { component score }\end{array}$ & $\begin{array}{c}\text { Heavy oil : kerosene } \\
(\%)\end{array}$ \\
\hline 1 & 38.459 & 52.087 & 90.546 & $100: 0$ \\
2 & 42.762 & 50.091 & 92.853 & $80: 20$ \\
3 & 48.479 & 48.621 & 97.100 & $60: 40$ \\
4 & 55.115 & 48.735 & 103.850 & $40: 60$ \\
5 & 64.579 & 52.064 & 116.643 & $20: 80$ \\
6 & 50.607 & 48.401 & 99.008 & - \\
\hline
\end{tabular}

Sample number 1 5: known sample; Sample number 6: unknown sample (content of heavy oil: $55 \%$ ).

$\left.\begin{array}{l}\log 97.100=60 \times a+b \\ \log 103.850=40 \times a+b\end{array}\right\} a=-1.460 \times 10^{-3} ; b=2.075 . \quad \log 99.008=\left(-1.460 \times 10^{-3}\right) \times x+2.075 ; x=54.79$ 
Table 5 Analytical results (content of heavy oil)

\begin{tabular}{cccr}
\hline $\begin{array}{c}\text { Unknown } \\
\text { sample } \\
\text { number }\end{array}$ & $\begin{array}{c}\text { Measurement } \\
\text { value (A), } \\
\%\end{array}$ & $\begin{array}{c}\text { Theoretical } \\
\text { value }(\mathrm{B}), \\
\%\end{array}$ & $\begin{array}{c}\mathrm{A}-\mathrm{B}, \\
\%\end{array}$ \\
\hline 1 & 25.8 & 25.0 & 0.8 \\
2 & 30.2 & 30.0 & 0.2 \\
3 & 38.5 & 40.0 & -1.5 \\
4 & 44.3 & 45.0 & -0.7 \\
5 & 54.8 & 55.0 & -0.2 \\
6 & 74.2 & 75.0 & -0.8 \\
7 & 93.1 & 93.0 & 0.1 \\
8 & 94.8 & 95.0 & -0.2 \\
\hline
\end{tabular}

Table 5 に示した. 又, 重油と灯油の混合比 $3: 7$ の試 料を用い，再現性を検討したところ，相対標準偏差 $1.58 \%(n=10)$ の結果が得られ，本方法は分離の不可能 な灯油と重油の混合比の決定に十分応用できることが明 らかとなった。

\section{文献}

1) 奥野忠一, 久米 均, 芳賀敏郎, 吉沢 正: “多変 量解析法”, (1971)，(日科技連).

2）奥野忠一, 芳賀敏郎, 矢島敬二, 奥野千恵子, 橋本 茂司, 古河陽子: “続多変量解析法”, (1976), (日 科技連)。

3) C. Chatfield, A. J. Collins: "Introduction to Multivariate Analysis", (1980), (Chapman \& Hall, London).

4) G. Blomquist, E. Johansson, B. Soderstrom, S. Wold: J. Chromatogr., 173, 7 (1979).

5) W. Windig, E. Jakab, J. M. Richards, H. L. C. Meuzelaar: Anal. Chem., 59, 317 (1987).

6) M. Hida, S. Okuyama, T. Mitsui, Y. Minami, Y. Fujimura: Chromatographia, 38, 436 (1994).

7) 奥山修司, 三井利幸, 藤村義和: 分析化学 (Bunseki Kagaku), 41, 43 ( 1992).

8) T. Mitsui, S. Okuyama, Y. Fujimura: Anal. Sci., 7, 941 (1991).

9) 奥山修司, 三井利幸, 藤村義和: 分析化学 (Bunseki Kagaku), 43, 383 (1994).

10) 三井利幸, 奥山修司, 藤村義和: 分析化学 (Bunseki Kagaku), 40, 389 (1991). Nagoya-shi, Aichi 460; ${ }^{* *}$ Department of Industrial Chemistry, Faculty of Engineering, University of Chubu, 1200, Matsumoto-cho, Kasugai-shi, Aichi 487)

When a mixture of heavy oil and kerosene was measured by GC, we could not accurately judge whether the measured material was heavy oil or kerosene because the respective chromatogram overlapped. Therefore, to analyze the blend composition ratio ( $\mathrm{v} / \mathrm{v}$ ) of heavy oil to kerosene, some chromatograms were made using mixture of heavy oil and kerosene with blend composition ratios. Each peak in the chromatograms was expressed by a relative value to provide data for calculation by principal component analysis. The blend composition ratio of an unknown sample was calculated more finely by factor score and dispersion of principal component. By this method, the blend composition ratios of heavy oil-kerosene mixtures could be determined with a high degree of accuracy.

(Received December 13, 1994)

(Accepted February 22, 1995)

\section{Keyword phrases}

blend composition of heavy oil and kerosene; GC; principal component analysis; factor score; dispersion of principal component. 